\title{
Point of care testing: randomised controlled trial of clinical outcome
}

\author{
Jason Kendall, Barnaby Reeves, Michael Clancy
}

Department of

Accident and

Emergency

Medicine, Bristol

Royal Infirmary,

Bristol BS2 8HW

Jason Kendall,

senior registrar in

accident and

emergency medicine

Michael Clancy,

consultant in accident

and emergency

medicine

Research and

Development

Support Unit,

Department of

Social Medicine,

University of

Bristol, Bristol

BS8 2PR

Barnaby Reeves,

senior lecturer in

health services

research

Correspondence to: Dr Kendall

Frenchay Hospital

NHS Trust, Bristol

BS16 1LE

jason.kendall@

cableinet.co.uk

BMJ 1998;316:1052-7

\begin{abstract}
Objectives: To describe the proportion of patients attending an accident and emergency department for whom blood analysis at the point of care brought about a change in management; to measure the extent to which point of care testing resulted in differences in clinical outcome for these patients when compared with patients whose samples were tested by the hospital laboratory.

Design: Open, single centre, randomised controlled trial. Blood samples were randomly allocated to point of care testing or testing by the hospital's central laboratory.

Setting: The accident and emergency department of the Bristol Royal Infirmary, a large teaching hospital which cares for an inner city population.

Subjects: Representative sample of patients who attended the department between April 1996 and April 1997 and who required blood tests. Data collection was structured in 8 hour blocks so that all hours of the day and all days of the week were equally represented.
\end{abstract}

Main outcome measures: The proportion of patients for whom point of care testing brought about a change in treatment in which timing was considered to be critical to clinical outcome. Mortality, the length of stay in hospital, admission rate, the amount of time spent waiting for results of blood tests, the amount of time taken to decide on management plans, and the amount of time patients spent in the department were compared between patients whose samples were tested at the point of care and those whose samples were sent to the laboratory.

Results: Samples were obtained from 1728 patients. Changes in management in which timing was considered to be critical occurred in 59 out of 859 (6.9\%, $95 \%$ confidence interval $5.3 \%$ to $8.8 \%)$ patients in the point of care arm of the trial. Decisions were made 74 minutes earlier ( $68 \mathrm{~min}$ to $80 \mathrm{~min}$,

$\mathrm{P}<0.0001$ ) when point of care testing was used for haematological tests as compared to central laboratory testing, 86 minutes earlier ( $80 \mathrm{~min}$ to 92 min, $\mathrm{P}<0.0001)$ for biochemical tests, and 21 minutes earlier ( -3 min to $44 \mathrm{~min}, \mathrm{P}=0.09$ ) for analyses of arterial blood gases. There were no differences between the groups in the amount of time spent in the department, length of stay in hospital, admission rates, or mortality.

Conclusion: Point of care testing reduced the time taken to make decisions on patient management that were dependent on the results of blood tests. It also brought about faster changes in treatment for which timing was considered to be critical in about $7 \%$ of patients. These changes did not affect clinical outcome or the amount of time patients spent in the department.

\section{Introduction}

Point of care testing is becoming increasingly popular; it has been defined as any laboratory test performed outside a hospital's central laboratory. ${ }^{1}$ Several factors are associated with the growing interest in point of care testing ${ }^{2}$; however, it is not clear whether the technology has been developed in response to clinical need or whether marketing strategies have led to the perception that there is a need for the technology. ${ }^{3}$ The availability of faster test results should expedite diagnosis and the initiation of treatment, both of which should have a positive impact on patient care. These benefits might also be expected to reduce the amount of time a patient spent waiting in an accident and emergency department. The Executive Health Technology Assessment Group of the NHS has concluded that an evaluation of the cost effectiveness of point of care testing is necessary. ${ }^{4}$ Such an evaluation would need to determine whether point of care testing benefits the patient and whether it is cost effective.

Previous evaluations of point of care testing have failed to address the issues of benefit to patients and cost effectiveness. ${ }^{5-10}$ We designed a randomised controlled trial to compare point of care testing with testing by the hospital laboratory in our accident and emergency department as part of a wider study which included an analysis of $\operatorname{costs}^{11}$ and an assessment of the accuracy and reproducibility of the results of the tests. ${ }^{12}$ This paper addresses issues of clinical outcome, and focuses on results obtained with a portable whole blood analyser designed for bedside use. We sought to describe the proportion of patients for whom point of care testing brought about a change in management in which timing was considered to be critical to clinical outcome. We also wanted to measure the extent to which such changes resulted in a difference in clinical outcome for patients when compared with patients whose samples were tested by the hospital laboratory.

\section{Subjects and methods}

\section{Study design}

Descriptive measures were used to evaluate changes in management that resulted from point of care testing. A randomised controlled trial was used to compare clinical outcomes. A sample of patients who presented to the accident and emergency department was selected between April 1996 and April 1997. Data were collected over 8 hour periods structured so that all hours of the day and all days of the week were represented equally. The 210 sampling periods (1680 hours) represented about $20 \%$ of the total number of hours in a year. All procedures were piloted before the start of the study, and data collection was performed by a single investigator (JK).

Patient information, the source of referral, the presenting complaint, and the date were recorded at the time of registration in the department (figure). The 


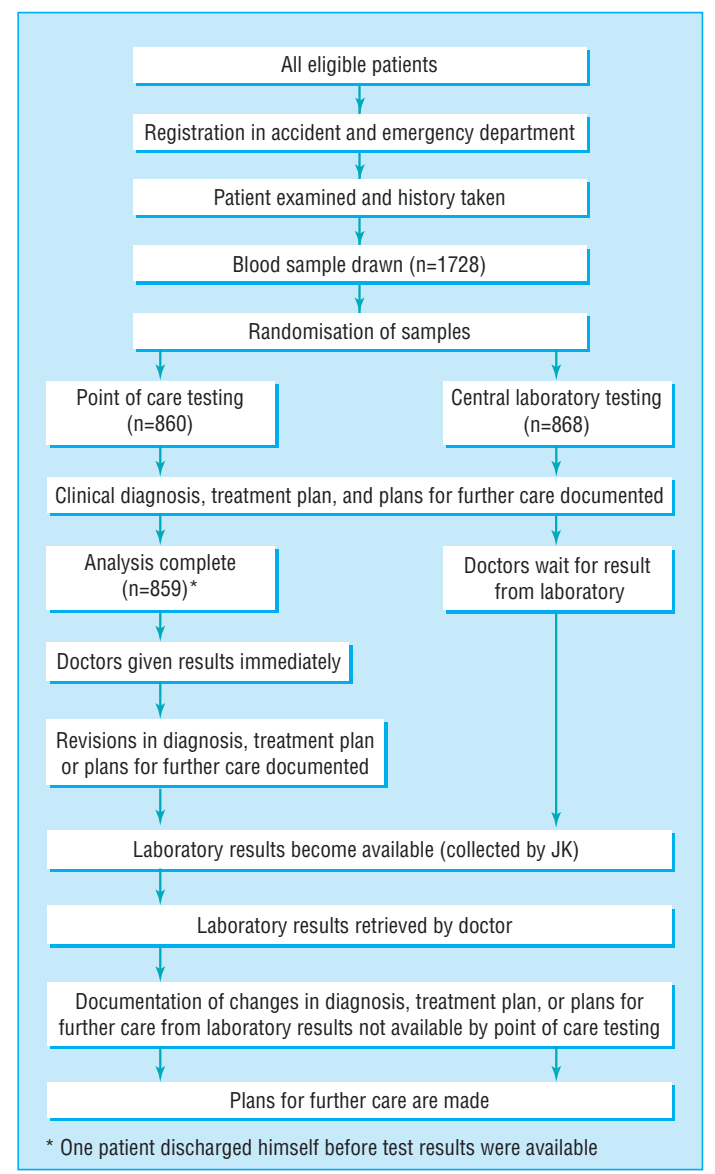

Design of randomised controlled trial comparing blood analysis at the point of care with testing by the central hospital laboratory

attending doctor assessed the patient and drew blood for urgent analysis if appropriate. In addition to samples for the central laboratory, the doctor also drew a $5 \mathrm{ml}$ heparinised sample for randomisation as part of the same venepuncture. The heparinised sample was immediately randomised to either point of care testing or testing by the central laboratory. All samples were randomised and no samples were withdrawn from the study. The results were recorded when the analysis was completed.

Blood samples were chosen as the units of randomisation. Randomisation of blocks was done with computer generated codes using MINITAB version 10 (State College, PA). Allocations were concealed in consecutively numbered, sealed opaque envelopes. All codes were generated by BR before the study; BR was not involved in data collection or patient care. For some patients more than one sample was analysed, for example when a venous blood profile and arterial blood gas analysis were required. However, only one sample, selected randomly, from each patient was included in the analyses reported here.

The attending doctor was interviewed by JK to determine the diagnosis, treatment plan, and plans for further care based on the doctor's clinical impression. The interview was brief and the same questions were asked of all doctors-what is the clinical differential diagnosis? what is your treatment plan? what is your plan for further care? Results from the point of care tests were given to the doctor immediately and their consequences for the patient's management were elicited by asking whether the results influenced the diagnosis, treatment plan, or plans for further care. Changes in any of these areas were recorded. When point of care results were not provided, because of randomisation, the patient was managed according to the initial plans.

Results from the hospital laboratory were automatically printed in the department ${ }^{13}$; they were retrieved by $\mathrm{JK}$, but were not necessarily given to the attending doctor. If a doctor had asked to be made aware of a result as soon as possible, the doctor was informed by JK when the results arrived. Otherwise, doctors had to approach JK for the results, mimicking the way in which they would have normally retrieved results. The time that the patient left the department, plans for future care, and the grade of the attending doctor were also documented.

The same procedure was followed for tests measuring arterial blood gas, except that samples were taken to the intensive therapy unit rather than being sent to the central laboratory; samples for point of care testing were obtained by taking a small amount of blood from the arterial blood gas syringe.

The study was approved by the local research ethics committee. Written consent was not required since no additional procedure was done, patients were not exposed to additional harm, and it would not have been practicable in many circumstances (for example, in the case of comatose patients). None the less, an information sheet was available if requested by patients.

\section{Patients}

The study population was a representative sample of patients seen at our accident and emergency department; the Bristol Royal Infirmary cares for an inner city population. Children are not seen in the department. About 50000 new patients are seen in accident and emergency each year; this includes patients referred to emergency by general practitioners for inpatient care. Blood samples from any patient seen in the department for whom an urgent blood test was requested were eligible for inclusion in the study. There were no exclusion criteria, and samples from all patients who attended during periods of data collection were included.

\section{Outcome measures}

Several outcomes were assessed (box). Mortality, the length of stay in hospital, admission rates from accident and emergency, the amount of time the doctor spent waiting for results from blood tests, the amount of time taken to decide on a management plan, and the amount of time the patient spent in accident and emergency were compared between those patients whose samples were analysed by point of care testing and those whose samples were analysed by the hospital laboratory. Differences between the two groups were anticipated to occur only in the time spent waiting for results from blood tests, the time taken to decide on a management plan, and the time spent in the department. 


\section{Outcome measures}

- Mortality

- Length of stay in hospital

- Admission rates from the accident and emergency department

- Amount of time spent waiting for results of blood tests

- Amount of time taken to decide on patient's management

- Amount of time patient spent in accident and emergency

- Proportion of patients for whom point of care testing changed diagnosis, treatment plan, or plans for further care

- Proportion of patients for whom point of care testing brought about time critical changes in treatment

\section{Point of care testing}

This study evaluated the i-STAT system (Princeton, NJ) for blood analysis, which is designed to be used at the patient's bedside. It is battery powered, hand held, and uses disposable cartridges that can perform several analyses simultaneously. ${ }^{14-17}$ Results are available in 2 minutes. We evaluated two cartridges. One cartridge measures concentrations of sodium, potassium, chloride, urea, and glucose; measures packed cell volume; and calculates haemoglobin concentration from packed cell volume. The other cartridge measures $\mathrm{pH}$, partial pressure of carbon dioxide, and partial pressure of oxygen; and calculates bicarbonate concentration, total carbon dioxide, base excess, and oxygen saturation.

\section{Changes in treatment}

Seventeen consultants and senior registrars experienced in emergency care used a visual analogue scale (range 0 to 10 ) to evaluate how important timing was to the clinical outcome for treatment changes instituted as a result of point of care testing (time critical changes). A score of zero indicated that the timing of the change was not critical; a score of 10 indicated that the change in treatment should be made as soon

Table 1 Characteristics of patients whose blood samples were allocated to point of care testing or to testing by the hospital's central laboratory. Values are numbers of patients (percentages) unless indicated otherwise

\begin{tabular}{lcc} 
& Point of care testing (n=860) & Laboratory testing (n=868) \\
\hline Mean (interquartile range) age (years) & $55(34-73)$ & $57(36-74)$ \\
\hline $\begin{array}{l}\text { Men } \\
\begin{array}{l}\text { Patients referred to emergency by } \\
\text { general practitioners }\end{array}\end{array}$ & $465(54)$ & $463(53)$ \\
\hline $\begin{array}{l}\text { Grade of attending doctor: } \\
\text { House officer }\end{array}$ & $451(52)$ & $428(49)$ \\
\hline Senior house officer & $98(11)$ & $89(10)$ \\
\hline Other & $661(77)$ & $683(79)$ \\
\hline Presenting complaint: & $101(12)$ & $96(11)$ \\
\hline Shortness of breath & & $99(11)$ \\
\hline Abdominal pain & $118(14)$ & $139(16)$ \\
\hline Chest pain & $139(16)$ & $142(16)$ \\
\hline Collapse & $137(16)$ & $72(8)$ \\
\hline Feeling unwell & $89(10)$ & $57(7)$ \\
\hline Overdose & $71(8)$ & $52(6)$ \\
\hline Trauma & $53(6)$ & $29(3)$ \\
\hline Gastrointestinal bleeding & $44(5)$ & $175(20)$ \\
\hline Other & $42(5)$ &
\end{tabular}

as the need for it was discovered. Interventions with median scores of 7 or greater were classed as time critical changes.

\section{Statistical analysis}

The sample size was chosen to estimate with a precision of $\pm 2 \%$ the proportion of patients for whom time critical changes in treatment occurred; this was considered to be sufficiently precise to judge the value of point of care testing. The results of the pilot study of 150 patients in July 1995 indicated that this proportion was about $9 \%$. A sample size of 1000 patients in the point of care arm of the study gives a $95 \%$ confidence interval of $\pm 1.8 \%$, which gave us a targeted sample size of 2000.

This sample size allowed the study to detect small differences in continuous outcomes between groups (for example, time spent in the department). However, the study had low power to detect a clinically important difference in mortality ( $20 \%$ power for a $1 \%$ difference, assuming an average mortality of $8 \%$ ). A difference in this outcome was not anticipated, and a prohibitively large sample (about 20000 patients) would have been required to have $80 \%$ power to detect a $1 \%$ difference. Comparisons between the two arms of the study were made using unpaired Student's $t$ tests for continuous outcomes and $\mathrm{z}$ tests for differences in proportions.

\section{Results}

Samples from 1728 patients were entered into the trial (figure). All patients entered into the study were accounted for. The characteristics of patients in the two arms of the study were similar (table 1).

The mean times between presentation and the attending doctor's awareness of test results are shown in table 2. Decisions on management were made 74 minutes earlier $(95 \%$ confidence interval $68 \mathrm{~min}$ to 80 $\min , \mathrm{P}<0.0001)$ when point of care testing was used for haematological tests as compared to central laboratory testing, 86 minutes earlier $(80 \mathrm{~min}$ to $92 \mathrm{~min}$, $\mathrm{P}<0.0001)$ for biochemical tests, and 21 minutes earlier ( $-3 \mathrm{~min}$ to $44 \mathrm{~min}, \mathrm{P}=0.09$ ) for analyses of arterial blood gases. The mean time spent between presentation and drawing of blood was similar between the two groups (difference between groups $1 \mathrm{~min},-4$ $\min$ to 6 min, $\mathrm{P}=0.78$ ); this shows that the differences in the amount of time taken to make a decision on management were the result of the faster availability of results with point of care testing.

The difference between groups in the time between a patient's presentation in the department and the time until the doctor's awareness of test results disguises a smaller difference between groups in the time until the doctor became aware of the results of arterial blood gas measurements $(5.5$ minutes, $\mathrm{P}<0.0001)$. Patients allocated to laboratory testing waited 14 minutes longer $(\mathrm{P}=0.18)$ for blood to be drawn than patients allocated to point of care testing.

Results from point of care testing influenced treatment in 120 out of 859 patients $(13.9 \%, 11.7 \%$ to $16.5 \%)$ and influenced plans for further care in 25 out of $859(2.9 \%, 1.9 \%$ to $4.3 \%)$. One patient discharged himself before test results were available. The influence of point of care testing on diagnosis, treatment plan, and plans for further care is shown in table 3 . 
Table 2 Mean time (minutes) between patient's presentation in the accident and emergency department, time until blood sample taken, and time until attending doctor's awareness of result of blood test for patients whose samples were allocated to point of care testing or to testing by the hospital's central laboratory

\begin{tabular}{|c|c|c|c|c|c|c|}
\hline & \multicolumn{2}{|c|}{ Point of care testing } & \multicolumn{2}{|c|}{ Laboratory testing } & \multicolumn{2}{|c|}{ Point of care $v$ laboratory testing } \\
\hline & No of patients & $\begin{array}{l}\text { Mean time } \\
(95 \% \mathrm{CI})\end{array}$ & $\begin{array}{c}\text { No of } \\
\text { patients }\end{array}$ & $\begin{array}{l}\text { Mean time } \\
(95 \% \mathrm{CI})\end{array}$ & $\begin{array}{c}\text { Difference between } \\
\text { means }(95 \% \mathrm{CI})\end{array}$ & $P$ value \\
\hline Time until blood sampling & $860^{*}$ & 65 (62 to 69$)$ & $868 \dagger$ & 66 (63 to 69$)$ & $1(-4$ to 6$)$ & 0.78 \\
\hline $\begin{array}{l}\text { Time until doctor aware of result of } \\
\text { arterial blood gas measurementł }\end{array}$ & 43 & 62 (48 to 91$)$ & 43 & $82(65$ to 100$)$ & 21 ( -3 to 44$)$ & 0.09 \\
\hline $\begin{array}{l}\text { Time until doctor aware of result of } \\
\text { haematological test }\end{array}$ & 815 & 80 (76 to 83 ) & 748 & 154 (150 to 159$)$ & 74 (68 to 80$)$ & $<0.0001$ \\
\hline $\begin{array}{l}\text { Time until doctor aware of result of } \\
\text { biochemical test }\end{array}$ & 815 & 80 (76 to 83 ) & 765 & 165 (160 to 170$)$ & 86 (80 to 92$)$ & $<0.0001$ \\
\hline
\end{tabular}

*Information is missing for one point of care patient who discharged himself before blood test results were available.

†Haematology and biochemistry results were not retrieved for all patients allocated to laboratory testing.

$\ddagger$ One point of care outlier, with a time to awareness of test result more than five times greater than the mean, was excluded from this comparison.

We suspected that point of care testing might influence treatment more frequently in some subgroups of patients than others, although we had no hypotheses about which subgroups would be most affected by point of care testing. There was pronounced variation in the proportion of patients for whom point of care results caused changes in treatment depending on the presenting complaint (table 4).

Frequencies of observed changes in treatment are categorised in table 5 . This table also shows the median score of the importance of the timing of the change in treatment as rated by the panel of clinicians. Altogether 59 out of 859 patients $(6.9 \%, 5.3 \%$ to $8.8 \%)$ whose samples were analysed at the point of care had changes in management in which timing was considered to be critical (score $\geqslant 7$ ). This summary statistic disguises disagreement between some members of the panel which evaluated the score for each treatment group.

There were no differences between the groups in the amount of time spent in accident and emergency, either for the sample as a whole or individually for patients admitted or discharged; there were also no differences in the length of inpatient stay, mortality, or admission rates (table 6).

\section{Discussion}

Point of care testing resulted in significantly faster decision making; experienced clinicians perceived that this produced a time critical clinical benefit for $6.9 \%$ of patients. Point of care tests influenced treatment in $14 \%$ of cases overall, although a proportion of these interventions were considered less clinically important by the panel. Unnecessary treatment was prevented in $3.6 \%$ of the patients whose blood samples were tested at the point of care; this may not have been a benefit for which timing was critical, but it represents a cost saving (quantification of which is outside the scope of this paper). Point of care testing also influenced plans for further care in $2.9 \%$ of patients.

There were no differences in the amount of time spent in the department, in admission rate, in the length of stay in hospital, or mortality between those patients whose samples were tested at the point of care and those whose samples were tested by the hospital laboratory. The lack of a difference in the amount of time spent in the department, despite a reduction in the time taken to make management decisions, implies that the availability of blood test results is not a rate limiting step. In our department, about $85 \%$ of patients are not discharged, and their further care is almost always limited by the availability of inpatient beds. There was no difference in the amount of time spent in the department for those patients who were discharged; this implies that the availability of blood test results is not the rate limiting step for these patients either.

It is important to consider the validity of our findings and their applicability in different settings. The structured sampling method used ensures that the findings are representative of patients attending the accident and emergency department at our hospital. Although there were no differences in admission rates or mortality between the two groups, this does not exclude the possibility that an important difference

Table 3 Number (percentage) of 859 patients whose samples were allocated to point of care testing for whom diagnosis, treatment plan, or plans for further care were changed because of the earlier availability of test results. Information is missing for one patient who discharged himself before test results were available

\begin{tabular}{lcc} 
Variable influenced by earlier results* & No of patients & Percentage $\mathbf{( 9 5 \%} \mathbf{C l )}$ \\
\hline Diagnosis or treatment or plans for further care & 202 & $23.5(20.7$ to 26.5$)$ \\
\hline Diagnosis & 133 & $15.5(13.1$ to 18.1$)$ \\
\hline Diagnosis alone & 65 & $7.6(5.9$ to 9.5$)$ \\
\hline Treatment & 120 & $13.9(11.7$ to 16.5$)$ \\
\hline Treatment alone & 50 & $5.8(4.4$ to 7.6$)$ \\
\hline Diagnosis and treatment & 61 & $7.1(5.5$ to 9.0$)$ \\
\hline Plans for further care & 25 & $2.9(1.9$ to 4.3$)$ \\
\hline Plans for further care alone & 16 & $1.9(1.1$ to 3.0$)$ \\
\hline Diagnosis and plans for further care & 1 & $0.1(0$ to 0.6$)$ \\
\hline Treatment and plans for further care & 3 & $0.4(0.1$ to 1.0$)$ \\
\hline Diagnosis and treatment and plans for further care & 5 & $0.6(0.2$ to 1.4$)$ \\
\hline
\end{tabular}

${ }^{*}$ Changes in diagnosis, treatment, or plans for further care could occur alone or in combination with other changes. For example, the diagnosis was changed in 133 patients, but diagnosis alone changed in 65 of the 133 ; for the other 68 patients treatment or plans for further care, or both, were changed in addition to the diagnosis.

Table 4 Presenting complaints of patients allocated to point of care testing by number of patients with complaint and number (percentage) of patients for whom point of care testing influenced treatment

\begin{tabular}{lcc} 
Presenting complaint & No influenced & Percentage $(\mathbf{9 5} \% \mathbf{~ C l})$ \\
\hline Shortness of breath $(\mathrm{n}=118)$ & 27 & $22.9(15.7$ to 31.5$)$ \\
\hline Abdominal pain $(\mathrm{n}=139)$ & 10 & $7.2(3.5$ to 12.8$)$ \\
\hline Chest pain $(\mathrm{n}=137)$ & 5 & $3.6(1.2$ to 8.3$)$ \\
\hline Collapse $(\mathrm{n}=89)$ & 12 & $13.5(7.2$ to 22.4$)$ \\
\hline Feeling unwell $(\mathrm{n}=71)$ & 10 & $14.1(7.0$ to 24.4$)$ \\
\hline Overdose $(\mathrm{n}=53)$ & 0 & $0(0 \text { to } 6.7)^{*}$ \\
\hline Trauma $(\mathrm{n}=44)$ & 4 & $9.1(2.5$ to 21.7$)$ \\
\hline Gastrointestinal bleeding $(\mathrm{n}=42)$ & 26 & $61.9(45.6$ to 76.4$)$ \\
\hline Other $(\mathrm{n}=167)$ & 26 & $15.6(10.4$ to 22.0$)$ \\
\hline
\end{tabular}

${ }^{*}$ One sided $97.5 \%$ confidence interval. 
Table 5 Number (percentage; $95 \% \mathrm{Cl}$ ) of times treatment was changed because of earlier availability of test results with point of care testing by type of treatment change and median (range) score on scale of the importance of the timing of the change. Scores $\geqslant 7$ (range 0 to 10) indicate that timing of the treatment change was considered to be critical

\begin{tabular}{lcc} 
Change in treatment & $\begin{array}{c}\text { Median (range) } \\
\text { score of importance } \\
\text { of timing }\end{array}$ & $\begin{array}{c}\text { No (\%; } \mathbf{9 5 \%} \text { Cl) of times } \\
\text { treatment changed (n=120) }\end{array}$ \\
\hline Start intravenous glucose & $10(9$ to 10$)$ & $3(2.5 ; 0.5$ to 7.1$)$ \\
\hline Start intravenous potassium & $7(1$ to 10$)$ & $14(11.7 ; 6.5$ to 18.8$)$ \\
\hline Start intravenous insulin & $8(4$ to 10$)$ & $7(5.8 ; 2.4$ to 11.6$)$ \\
\hline Start intravenous hydrocortisone & $5(0$ to 10$)$ & $1(0.8 ; 0$ to 4.6$)$ \\
\hline Start intravenous aminophylline & $6(2$ to 10$)$ & $1(0.8 ; 0$ to 4.6$)$ \\
\hline Start intravenous antibiotics & $3(0$ to 10$)$ & $1(0.8 ; 0$ to 4.6$)$ \\
\hline Stop intravenous potassium & $7(2$ to 10$)$ & $1(0.8 ; 0$ to 4.6$)$ \\
\hline Stop intravenous insulin & $8(3$ to 10$)$ & $2(1.7 ; 0.2$ to 5.9$)$ \\
\hline Start intravenous infusion for dehydration & $5(1$ to 7$)$ & $18(15.0 ; 9.1$ to 22.7$)$ \\
\hline Start intravenous infusion in diabetic ketoacidosis & $9(4$ to 10$)$ & $3(2.5 ; 0.5$ to 7.1$)$ \\
\hline Stop intravenous infusion & $3(0$ to 6$)$ & $2(1.7 ; 0.2$ to 5.9$)$ \\
\hline Change rate of intravenous infusion & $3(0$ to 7$)$ & $7(5.8 ; 2.4$ to 11.6$)$ \\
\hline Start urgent blood transfusion & $8(1$ to 10$)$ & $11(9.2 ; 4.7$ to 15.8$)$ \\
\hline Stop inappropriate blood transfusion & $5(1$ to 10$)$ & $26(21.7 ; 13.7$ to 30.1$)$ \\
\hline Start oxygen therapy & $10(7$ to 10$)$ & $2(1.7 ; 0.2$ to 5.9$)$ \\
\hline Change oxygen therapy & $9(4$ to 10$)$ & $11(9.2 ; 4.7$ to 15.8$)$ \\
\hline Intubate or ventilate & $10(4$ to 10$)$ & $5(4.2 ; 1.4$ to 9.5$)$ \\
\hline Start intravenous bicarbonate & $6(0$ to 10$)$ & $1(0.8 ; 0$ to 4.6$)$ \\
\hline Start oral potassium & $1(0$ to 6$)$ & $3(2.5 ; 0.5$ to 7.1$)$ \\
\hline Start fluid restriction & $3(0$ to 7$)$ & $1(0.8 ; 0$ to 4.6$)$ \\
\hline
\end{tabular}

*Treatment was changed more than once for some patients because of point of care results. Only the treatment change that was most dependent on time is shown for each patient

may exist; however, the estimates of differences in outcome are close to zero.

Confounding was minimised by the design of the study and the large sample size. Bias was minimised by appropriate design features: randomisation was carefully concealed from the investigator; only one investigator was involved in data collection; and all patients entered into the trial were accounted for. However, the open design of the trial is a potential source of bias since documenting changes in management required $\mathrm{JK}$ to interview the attending doctors. It is possible that JK may have influenced doctors' responses by altering his questioning as a result of knowing a patient's allocation. This possibility was minimised by using a standard set of neutral questions.

The applicability and relevance of the findings needs to be considered carefully, given the diversity of care provided by accident and emergency departments. The precise research question was debated because it was easy to speculate when point of care testing might be more useful or less useful. However, we decided it would be most valuable to study a completely representative sample that could act as a baseline for future study. Our findings suggest that point of care testing may be clinically beneficial for some presenting complaints. Further studies are required to investigate this.

We cannot be certain that samples from all eligible patients were included. The representativeness of the sample could have been undermined if treatment changes would have been initiated earlier as a result of point of care testing in a disproportionate number of patients who were eligible for the study but were not included. Patients may have been missed if a blood sample was taken by a paramedic or by a doctor who forgot to take an appropriate sample, or if the investigator was involved in the emergency resuscitation of a patient where duty of care took precedence over the study. Patients who were missed because their blood sample was taken by a paramedic or by a doctor who neglected to take an appropriate sample are unlikely to have had a probability of a change in treatment that was different from the study population. Although patients whom the investigator helped to resuscitate may have had a higher probability of benefit, there were fewer than 5 such patients during the study.

We are confident that our findings are a representative, valid, and precise estimate of the proportion of patients seen in accident and emergency for whom point of care testing would result in a clinically important reduction in the time taken to make differential diagnoses and treatment decisions. This proportion is unlikely to vary more than the estimate of precision of the study unless a department has restrictions on the types of patients that it accepts. Our findings can also be used to interpret the consequences of implementing point of care testing when the availability or performance of local central laboratory testing differs from our institution. Where central laboratory times might vary in a clinically important way, they can be estimated locally on relatively small samples. Local estimates, in conjunction with our findings, can be used to evaluate the benefit of point of care testing in the local setting. This study was unable to quantify potential benefit in settings where the rate limiting step in time to making arrangements for further care is not the availability of beds.

Maddi Barley, of the Clinical Audit Department, United Bristol Hospitals Trust, helped develop the database. We would also like to acknowledge the support of all of our clinical colleagues who worked in the accident and emergency department during the period of data collection.

Table 6 Comparison of the mean total time patients spent in the emergency department, length of stay in hospital, number of admissions, and mortality for patients whose samples were allocated to point of care testing or to laboratory testing

\begin{tabular}{|c|c|c|c|c|c|c|}
\hline & \multicolumn{2}{|c|}{ Point of care testing } & \multicolumn{2}{|c|}{ Laboratory testing } & \multicolumn{2}{|c|}{ Point of care $v$ laboratory testing } \\
\hline & $\begin{array}{c}\text { No of } \\
\text { patients* }\end{array}$ & $\begin{array}{c}\text { Mean }(95 \% \mathrm{CI}) \\
\text { or No }(\%)\end{array}$ & $\begin{array}{c}\text { No of } \\
\text { patients }\end{array}$ & $\begin{array}{l}\text { Mean }(95 \% \mathrm{Cl}) \\
\text { or No }(\%)\end{array}$ & $\begin{array}{c}\text { Difference } \\
(95 \% \mathrm{CI})\end{array}$ & $P$ value \\
\hline $\begin{array}{l}\text { Mean }(95 \% \mathrm{Cl}) \text { time spent in } \\
\text { emergency department ( } \mathrm{min})\end{array}$ & 859 & 188 (181 to 194$)$ & 868 & 193 (186 to 200$)$ & $5(-5$ to 15$)$ & 0.30 \\
\hline $\begin{array}{l}\text { Mean }(95 \% \mathrm{Cl}) \text { length of stay in } \\
\text { hospital (days) } \dagger\end{array}$ & 730 & $7.8(6.9$ to 8.6$)$ & 720 & $8.3(7.5$ to 9.1$)$ & $0.5(-1$ to 2$)$ & 0.37 \\
\hline No (\%) admissions & 860 & $733(85.2)$ & 868 & $725(83.5)$ & $1.7(-1.7$ to 5.1$)$ & 0.33 \\
\hline No (\%) deathsł & 859 & $55(6.4)$ & 867 & $48(5.5)$ & $0.9(-1.4$ to 3.1$)$ & 0.45 \\
\hline
\end{tabular}

${ }^{*}$ One patient discharged himself before test results became available.

flnformation on length of stay in hospital was not available for three point of care patients and three patients allocated to laboratory testing who were transferred to other hospitals. Information was missing from the hospital information system for two additional patients allocated to laboratory testing.

flnformation was not available for one point of care patient and one patient allocated to laboratory testing because they were transferred to other hospitals. 
Contributors: JK, BR, and MC were all involved in designing and executing the study as well as in writing the paper. JK collected the data and is guarantor for the paper.

Funding: During data collection, JK's salary was provided by a grant from Hewlett Packard UK.

Conflict of interest: The i-STAT system is manufactured by Hewlett Packard. Hewlett Packard was not involved in any stage of the study design, execution, analysis of data, writing up of the findings, or decisions about publication, although comments on the manuscript were sought as a matter of courtesy to the sponsor.

1 Santrach P, Burritt M. Point of care testing. Mayo Clin Proc 1995;70:493-4

2 Fleisher M. Point of care testing: does it really improve patient care? Clin Biochem 1993;26:6-8.

3 Jatlow P. Point of care laboratory testing in the emergency department. Am J Clin Pathol 1993;100:591.

4 Brown H. Near patient tests are poorly evaluated. BMJ 1997;314:1785.

5 Sands V, Auerbach P, Birnbaum J, Green M. Evaluation of a portable clinical blood analyser in the emergency department. Acad Emerg Med 1995;2:172-8

6 Tsai W, Nash D, Seamonds B, Weir G. Point-of-care versus central laboratory testing: an economic analysis in an academic medical center. Clin Ther 1994;16:898-911.

7 Parvin C, Lo S, Deuser S, Weaver L, Lewis L, Scott M. Impact of point of care testing on patients' length of stay in a large emergency department. Clin Chem 1996;42:711-7.

8 Fleisher M, Schwartz M. Automated approaches to rapid-response testing: a comparative evaluation of point of care and centralised laboratory testing. Am J Clin Pathol 1995;104:S18-25.

9 Saxena S, Wong E. Does the emergency room need a dedicated stat laboratory? Continuous quality improvement as a management tool for the clinical laboratory. Am J Clin Pathol 1993;100:606-10.

10 Frankel H, Rozycki G, Ochsner M, McCabe J, Harviel J, Jeng J, et al. Minimising admission laboratory testing in trauma patients: use of a microanalyser. J Trauma 1994;37:728-36.

11 Kendall JM, Bevan G, Clancy M. A randomised controlled trial of point of care testing in an accident and emergency department: a cost analysis. $J$ Health Services Res Policy (in press).

12 Bingham D, Kendall JM, Clancy M. The portable laboratory, fact or fiction: an evaluation of the accuracy and reproducibility of i-STAT. Ann Clin Biochem (in press).

13 Clancy MJ, Bingham D. Benefits of immediate printing of blood test results within an accident and emergency department. J Accident Emerg Med 1996;13:149-50.
Key messages

- Point of care testing reduced the amount of time doctors spent waiting for results of blood tests when compared to the time spent waiting for results from the hospital laboratory in an accident and emergency department

- The time taken to decide on a management plan was also reduced as a result of the shorter time spent waiting for results of point of care tests

- About $7 \%$ of patients who needed urgent blood testing had changes in treatment in which timing was considered to be critical when point of care testing was used

- Patients did not spend less time in the accident and emergency department even when test results were available more quickly and patient management decisions were made more quickly. This suggests that the availability of test results is not the factor which slows down the arrangement of further care

- Improvements in process, such as a reduction in the time doctors wait for test results and the ability to make clinical decisions more quickly, do not seem to improve clinical outcome in this sample of patients

14 Zaloga G, Hill T, Strickland R, Kennedy D, Visser M, Ford K, et al. Bedside blood gas and electrolyte monitoring in critically ill patients. Crit Care Med 1989;17:920-5.

15 Jacobs E, Vadasi E, Sarkozi L, Colman N. Analytical evaluation of i-STAT portable clinical analyser and use by non-laboratory health care professionals. Clin Chem 1993;39:1069-74.

16 i-STAT Corporation. i-STAT Manual. Princeton, NJ: 1996

17 Woo J, McCabe J, Chauncey D, Schug T, Henry J. The evaluation of a portable clinical analyser in the emergency department. Am J Clin Pathol 1993;100:599-605.

(Accepted 5 December 1997)

\title{
Aspirin for prophylaxis against headache at high altitudes: randomised, double blind, placebo controlled trial
}

\author{
Martin Burtscher, Rudolf Likar, Werner Nachbauer, Michael Philadelphy
}

At altitudes of $3000-5000 \mathrm{~m}$ about $20-50 \%$ of skiers and mountaineers experience headache, the main symptom of acute mountain sickness. ${ }^{1}$ Although most mountaineers know that they should avoid climbing great heights too early on and too fast, they may not always act accordingly. The use of drugs to prevent and treat headaches at high altitudes is therefore widespread, aspirin being one of the most commonly taken. We tested the efficacy of aspirin as prophylaxis against headache at high altitudes.

\section{Subjects, methods, and results}

Twenty nine volunteers with a history of headache at high altitude were randomly assigned in a double blind fashion to receive placebo (eight men, six women, mean age 38 (SD 12) years) or $320 \mathrm{mg}$ aspirin (nine men, six women, mean age 38 (14) years). After examination at low altitude $(600 \mathrm{~m})$, subjects were transported to high altitude $(3480 \mathrm{~m})$ for 24 hours. We gave them three tablets, one every 4 hours, starting 1 hour before arrival at high altitude. We scored headache on a four-point scale $(0=$ none, $1=$ mild,
$2=$ moderate, $3=$ severe) and measured heart rate, blood pressure, and arterial oxygen saturation 1 hour before and 3, 7, 10, and 19 hours after arrival. In addition, subjects exercised for 2 minutes by stepping 60 times up and down a $24 \mathrm{~cm}$ step, at low altitude and within 2-5 hours after arrival at high altitude during which we continuously monitored gas exchange, heart rate, and oxygen saturation.

Seven subjects given placebo and only one given aspirin developed mild to severe headache $(\mathrm{P}=0.01$ for differences in proportions). Although mean oxygen saturation was not different between the two groups 3 hours after arrival at high altitude, the individual values were accurate predictors of the subsequent development of headache. Those who had taken aspirin developed headache at lower oxygen saturation than those who had taken placebo ( $<83 \% v<88 \%$; figure). The difference between mean heart rates at the end of the exercise test at high and low altitudes was smaller in those who had taken aspirin (134 (7) $v 118$ (10) beats/ $\mathrm{min})$ than in those who had taken placebo (142 (13) $v$ 116 (15)) $(\mathrm{P}=0.01$, analysis of variance for repeated measures), in whom ventilation responses to exercise

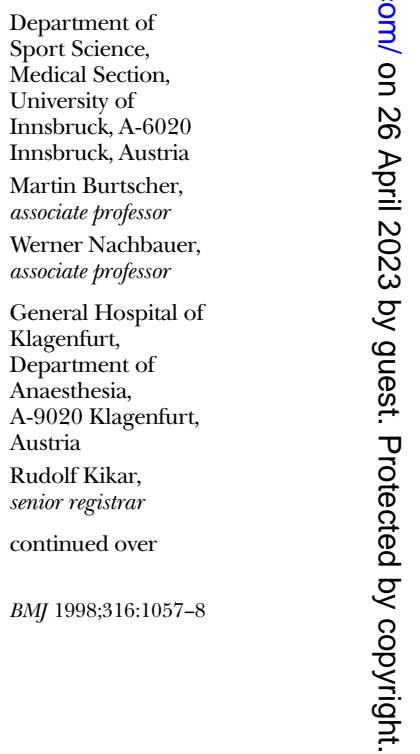

